\title{
Modeling systems relevant to the biodiesel production using the CPA equation of state. Part 2. Systems with supercritical $\mathrm{CO} 2$
}

Tsivintzelis, loannis; Ali, Shahid; Kontogeorgis, Georgios M.

\section{Published in:}

Fluid Phase Equilibria

Link to article, DOI:

10.1016/j.fluid.2019.112337

Publication date:

2020

Document Version

Peer reviewed version

Link back to DTU Orbit

Citation (APA):

Tsivintzelis, I., Ali, S., \& Kontogeorgis, G. M. (2020). Modeling systems relevant to the biodiesel production using the CPA equation of state. Part 2. Systems with supercritical $\mathrm{CO}_{2}$. Fluid Phase Equilibria, 504, [112337]. https://doi.org/10.1016/j.fluid.2019.112337

\section{General rights}

Copyright and moral rights for the publications made accessible in the public portal are retained by the authors and/or other copyright owners and it is a condition of accessing publications that users recognise and abide by the legal requirements associated with these rights.

- Users may download and print one copy of any publication from the public portal for the purpose of private study or research.

- You may not further distribute the material or use it for any profit-making activity or commercial gain

- You may freely distribute the URL identifying the publication in the public portal 


\title{
Modeling Systems Relevant to the Biodiesel Production Using the CPA Equation of State. Part 2. Systems with Supercritical $\mathrm{CO}_{2}$
}

\author{
Ioannis Tsivintzelis ${ }^{* 1,2}$, Shahid Ali ${ }^{1,3}$ and Georgios M. Kontogeorgis ${ }^{1}$ \\ ${ }^{1}$ Center for Energy Resources Engineering (CERE), Department of Chemical and \\ Biochemical Engineering, Technical University of Denmark, DK-2800 Kgs. Lyngby, \\ Denmark \\ ${ }^{2}$ Aristotle University of Thessaloniki, Department of Chemical Engineering, 54124, \\ Greece \\ ${ }^{3}$ Current address: Department of Energy Technology, Aalborg University, \\ Pontoppidanstrcede 111, 9220 Aalborg, Denmark
}

*Corresponding author: Ioannis Tsivintzelis: E-mail: gtsivint@eng.auth.gr

\begin{abstract}
The CPA EoS is applied to binary mixtures of $\mathrm{CO}_{2}$ with fatty acids and their methylor ethyl- esters. The model, using one temperature independent binary interaction parameter, satisfactorily describes the phase behavior of such systems. Correlations of the binary interaction parameters with the number of esters' or acids' carbon atoms, or with the number of double bonds for compounds with the same number of carbon atoms, were developed in order to make predictions feasible in cases of lack of experimental data. Subsequently, the model was applied for predicting the phase behavior of ternary and multicomponent mixtures. The model rather satisfactorily predicts the vapor-liquid equilibrium of such systems. In accordance with the first part of this series of articles [Tsivintzelis et al. 430 (2016) 75-92], since the binary parameters were optimized solely using experimental data for binary mixtures, CPA results for the ternary mixtures are pure predictions.
\end{abstract}

Keywords: Supercritical $\mathrm{CO}_{2}$, Biodiesel, Fatty acids, Esters of Fatty acids, CPA, Phase Equilibrium

\section{Introduction}

The processing of vegetable oils with supercritical $\mathrm{CO}_{2}$ is attracting considerable attention mainly from the food, but also from the pharmaceutical, nutraceutical and biodiesel industries. The extraction of vegetable oils, the selective extraction of valuable ingredients and the fractionation of fatty acids and fatty acid esters are now well studied processes [1]. However, such compounds are found in many pharmaceutical or nutraceutical products of high added value, where the purity of the products is of high importance, rendering such applications ideal for processing with supercritical $\mathrm{CO}_{2}$ (which is nontoxic and can be easily separated from the final product material). 
Biodiesel is usually produced from vegetable oils by the transesterification of triglycerides using excess of methanol or ethanol. Recently, several studies investigated the potential of using supercritical $\mathrm{CO}_{2}$ as a co-solvent or as a reaction medium in the transesterification reactions [2-4]. Moreover, supercritical $\mathrm{CO}_{2}$ has also been suggested for biodiesel purification processes, aiming to the removal of glycerol and other polar contaminants [5].

Vegetable oil and biodiesel related mixtures include many compounds such as fatty acids, alkyl esters of fatty acids, glycerides, glycerol, low molecular weight alcohols and water. The thermodynamic modeling of such multicomponent mixtures is rather demanding, mainly due to the highly non-ideal behavior of some systems (for example aqueous systems of organic acids), but also due to the lack of data, or due to the quality of some available data. In more detail, mainly due to the decomposition of high molecular weight compounds at relatively high temperatures, there is lack of experimental data for critical temperatures or vapor pressures for fatty acids, glycerides and esters of fatty acids. Moreover, such compounds are usually obtained in mixtures of various isomers, since compounds of the same family and similar molecular weight present similar physical properties rendering their purification rather demanding. Consequently, experimental data are often based on low purity samples. Furthermore, many mixtures of interest are reactive (i.e. mixtures of esters with alcohols, or alcohols with fatty acids) rendering the measurement of the phase behavior very demanding. Nevertheless, many experimental data of good quality were measured during the last years.

The Cubic-Plus-Association (CPA) equation of state (EoS) [6] is a combination of the SRK cubic Equation of State (EoS) with the association term that is used in the SAFT type models [11] (developed by Wertheim [7-10]). The CPA model has been extensively reviewed in literature [12-16] and is not presented here. Readers are referred to the original studies and should be familiar with concepts such as the association schemes and the combining rules used in the CPA model [12-16].

This study is a continuation of our previous study in modeling mixtures relevant to the production of biodiesel [17], where CPA pure fluid parameters for fluids, such as glycerides, organic acids, heavy esters and glycerol, were presented, along with trends of those parameters with the van der Waals volume. The performance of CPA in modeling the vapor - liquid (VLE) and the liquid - liquid equilibrium (LLE) of binary mixtures, containing water, glycerol, or alcohols with fatty acids, esters of fatty acids or glycerides, was evaluated and trends of such binary parameters with the molecular weight (or the carbon chain length) were obtained. Such estimated binary parameters and their correlations were used for predicting the liquid-liquid equilibrium of ternary and multicomponent mixtures [17].

In this study we present the application of CPA to describe binary, ternary and multicomponent systems that contain $\mathrm{CO}_{2}$ and biodiesel-related compounds (fatty acids, heavy esters and methanol). Similarly to our previous study, emphasis is put on the establishment of systematic trends of the binary interaction parameters, in order to 
enhance the predicting ability of the model for multicomponent systems. Moreover, all results for the ternary and multicomponent systems are considered as pure predictions, since binary parameters fitted only to binary data are used and there is no fine tuning of any parameter based on ternary or multicomponent data.

\section{Binary systems with $\mathrm{CO}_{2}$}

Having the pure fluid parameters for low molecular weight acids or fatty acids and their esters from our previous study [17], the CPA EoS was applied to correlate the vapor - liquid equilibrium (VLE) of their mixtures with $\mathrm{CO}_{2}$. In more detail, the pure fluid parameters for saturated esters and unsaturated esters were adopted from Tables 2 and 3 , respectively, of reference 17 , while parameters for acids were adopted from Table 4 of reference 17 . The pure fluid parameters of $\mathrm{CO}_{2}$ and methanol were adopted from literature [18]. In all cases one temperature independent binary interaction parameter $\left(k_{i j}\right)$ was used.

\section{1. $\mathrm{CO}_{2}$ - Esters of Fatty Acids}

Mixtures of $\mathrm{CO}_{2}$ with methyl- and ethyl- esters of low molecular acids and fatty acids were modeled using available experimental data from literature. Such data, especially for mixtures with high molecular weight fatty acids, are in some cases contradictory and, thus, data from different studies are not in good agreement to each other. An example is shown in Figure 1. Nevertheless, many experimental data of good quality were measured during the last years.

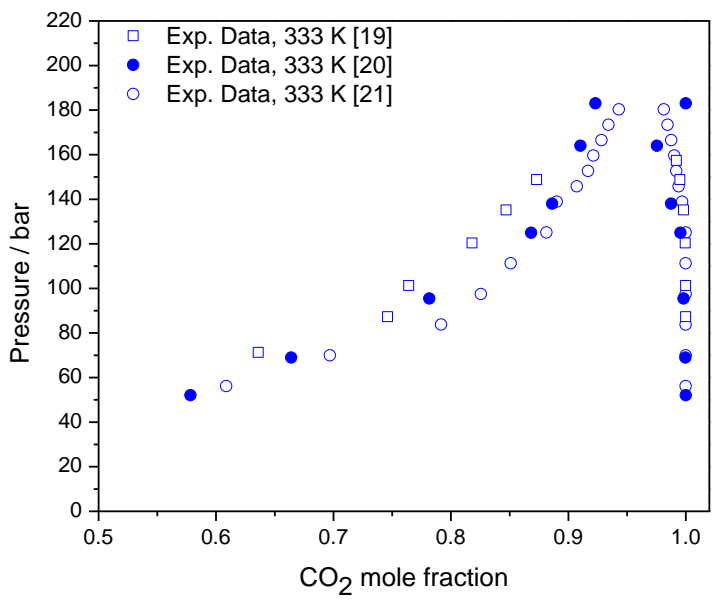

(a)

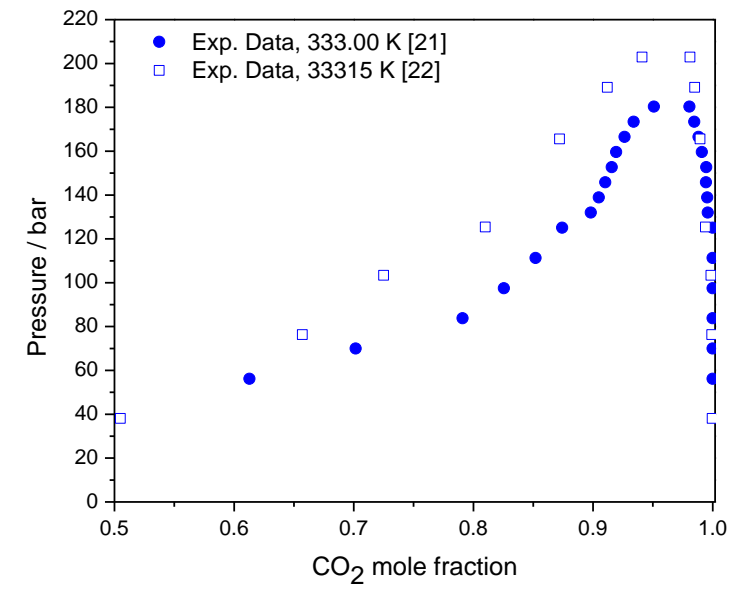

(b)

Figure 1. $\mathrm{CO}_{2}$ - methyl oleate (a) and $\mathrm{CO}_{2}$ - methyl linoleate (b) VLE. Experimental data from various literature sources [19-22].

The CPA equation of state was applied to model all the systems for which it was possible to find experimental data. In all cases, $\mathrm{CO}_{2}$ and esters were modeled as inert compounds and one temperature independent binary interaction parameter $\left(k_{i j}\right)$ was optimized by the experimental data. The results are presented in Table 1 . The model 
satisfactorily describes the vapor (fluid) - liquid equilibrium of such systems. Higher deviations are obtained for the ester fraction of the vapor phase. Most of such deviations are due to some low pressure data, where the ester mole fraction of the vapor phase is very low (of the order of $10^{-4}$ or less). However, they also reveal the difficulty in modeling such low concentrations using only one temperature independent parameter with the CPA model.

Since the aim of this study is to enhance the predictive capabilities of the CPA model, the estimated binary parameters of Table 1 are plotted against the number of carbon atoms of esters in Figure 2a. The $k_{i j}$ s for saturated esters with more than eight carbon atoms, as for almost all biodiesel related compounds (see Tsivintzelis et al. [17]), follow a linear trend, which is more pronounced for high molecular weight compounds. In Figure $2 \mathrm{~b}$, the $k_{i j}$ s are plotted against the number of double bonds for methyl- and ethyl- esters of C18-x fatty acids, i.e. 18 is the number of carbon atoms and $x$ is the number of double bonds. As it was expected, the binary interaction parameter becomes lower as the number of double bonds increases. This is reasonable, since interactions that are more favorable should occur between the $\pi$-electrons of ester molecules and the charged (positive) carbon atom of $\mathrm{CO}_{2}$. Results for the vapor liquid equilibrium of $\mathrm{CO}_{2}$ - methyl and ethyl- esters are presented graphically in Figures 3-7.

Table 1. Binary interaction parameters $\left(k_{i j}\right)$ and deviations from experimental data for $\mathrm{CO}_{2}(1)$ - Methyl- or Ethyl- Esters (2).

\begin{tabular}{|c|c|c|c|c|c|c|}
\hline Ester & $\begin{array}{c}\text { Temp. } \\
\text { Range / K }\end{array}$ & $k_{i j}$ & $\begin{array}{c}\% \mathrm{AAD}^{\mathrm{a}} \text { in } \\
\mathrm{x}_{1}\end{array}$ & $\begin{array}{c}\% \mathrm{AAD}^{\mathrm{a}} \\
\text { in } \mathrm{y}_{1}\end{array}$ & $\begin{array}{l}\% \mathrm{AAD}^{\mathrm{a}} \\
\text { in } \mathrm{y}_{2}\end{array}$ & References \\
\hline \multicolumn{7}{|l|}{$\begin{array}{l}\mathrm{CO}_{2}(1)-\text { Methyl } \\
\text { Esters (2) }\end{array}$} \\
\hline Methyl Ethanoate & $298-313$ & -0.0078 & 11 & 0.36 & 19 & [23] \\
\hline Methyl Laurate & $323-333$ & 0.0520 & 4.8 & 6.4 & 59 & [24] \\
\hline Methyl Myristate & $323-333$ & 0.0580 & 7.8 & 0.13 & 80 & {$[19,25]$} \\
\hline Methyl Palmitate & $323-343$ & 0.0653 & 13 & 0.11 & 48 & {$[19,25]$} \\
\hline Methyl Stearate & $323-343$ & 0.0715 & 10 & 0.18 & 33 & [19] \\
\hline Methyl Oleate & $323-343$ & 0.0566 & 9.5 & 0.20 & 67 & [19-22] \\
\hline Methyl Linoleate & 333 & 0.0480 & 8.8 & 0.17 & 77 & {$[21,22]$} \\
\hline \multicolumn{7}{|l|}{$\begin{array}{c}\mathrm{CO}_{2}(1)-\text { Ethyl } \\
\text { Esters (2) }\end{array}$} \\
\hline Ethyl Ethanoate & $323-393$ & -0.0550 & 10 & 1.3 & 31 & {$[26,27]$} \\
\hline Ethyl Propanoate & $333-373$ & -0.0414 & 3.8 & 0.80 & 62 & {$[27]$} \\
\hline Ethyl Octanoate & $318-328$ & 0.0299 & 2.4 & 2.3 & 49 & [28] \\
\hline Ethyl Decanoate & $318-328$ & 0.0381 & 2.4 & 1.9 & 75 & [28] \\
\hline Ethyl Dodecanoate & $318-328$ & 0.0481 & 2.5 & 2.6 & 65 & [29] \\
\hline Ethyl Oleate & $323-333$ & 0.0632 & 9.4 & 10 & 29 & [30] \\
\hline Ethyl Linoleate & $323-333$ & 0.0422 & 6.3 & 0.13 & 40 & [30] \\
\hline
\end{tabular}

a\%AAD $=\frac{1}{n} \sum_{i}\left|\frac{X_{i}^{c a l}-X_{i}^{\text {exp }}}{X_{i}^{\exp }}\right| \times 100$ where $X$ stands for the $\mathrm{CO}_{2}$ mole fraction of the liquid phase $\left(x_{1}\right)$ and the ester mole fraction $\left(y_{2}\right)$ of the vapor phase, while $n$ is the number of experimental data points 


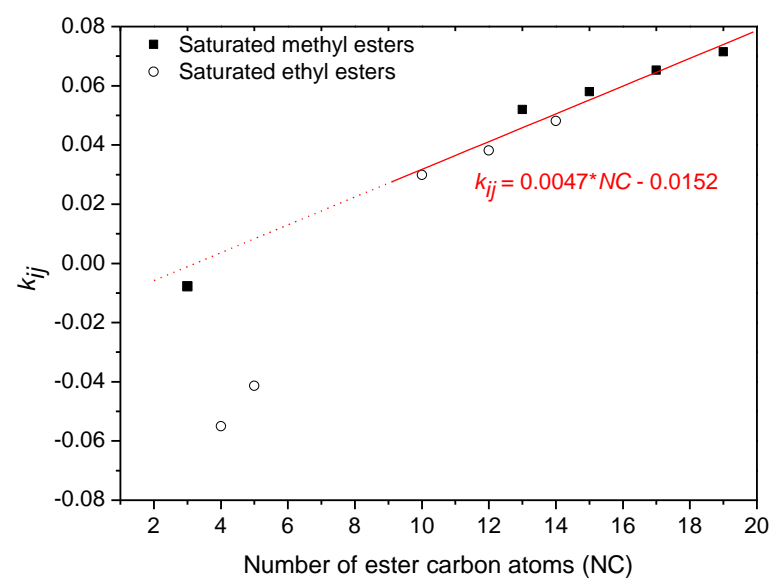

(a)

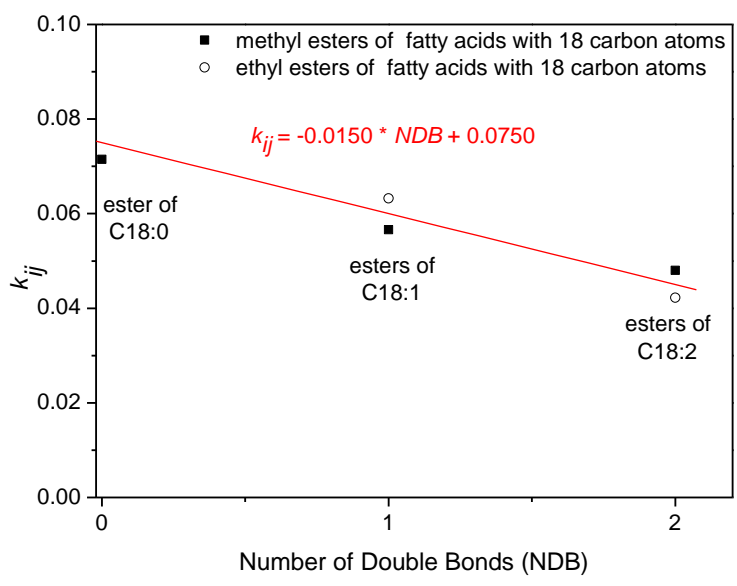

(b)

Figure 2. Binary interaction parameters $\left(k_{i j} \mathrm{~s}\right)$ against the number of ester carbon atoms (NC) (a) and against the number of double bonds (NDB) for methyl- and ethyl- esters of C18- $x$ fatty acids (stearic acid (C18:0), oleic acid (C18:1) and linoleic acid (C18:2)) (b).

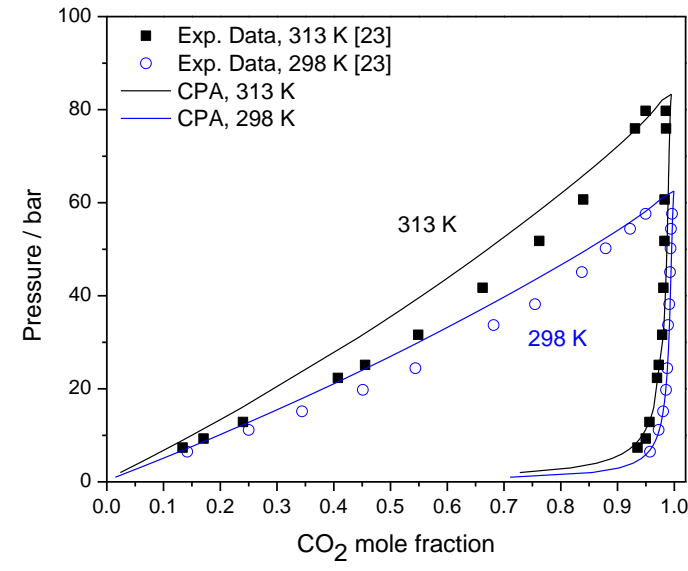

(a)

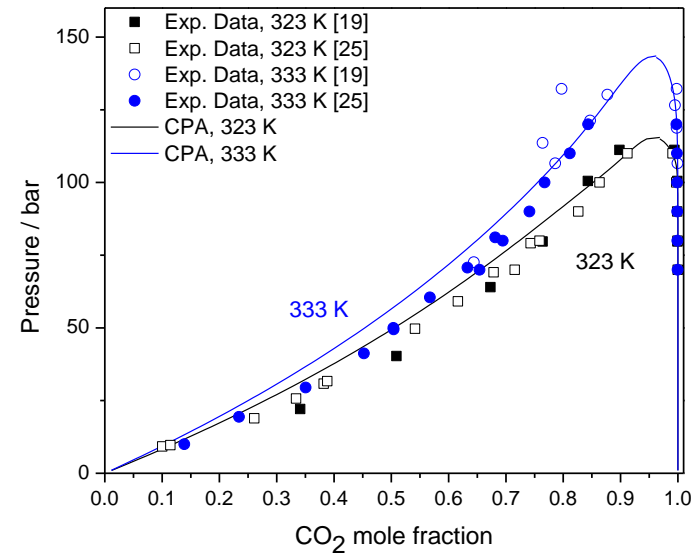

(c)

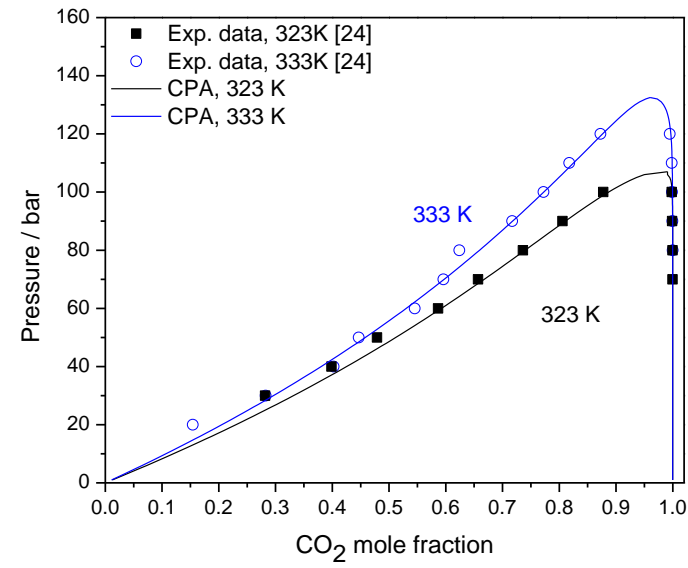

(b)

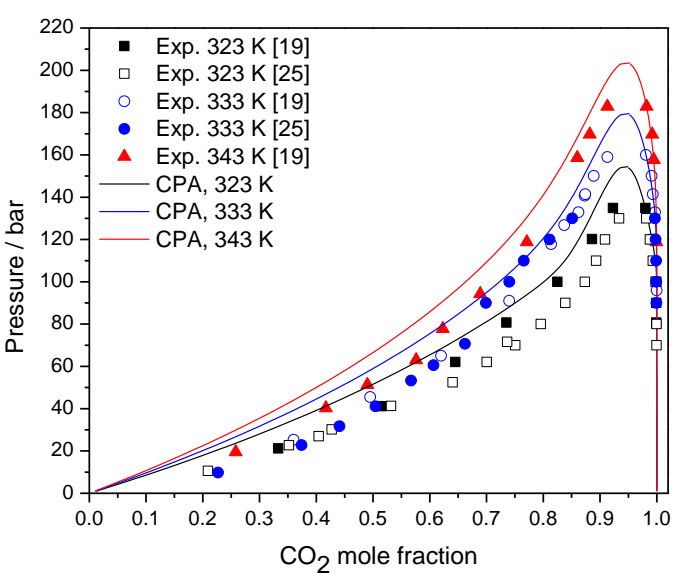

(d)

Figure 3. $\mathrm{CO}_{2}-$ methyl- esters VLE. Experimental data (points) and CPA calculations (lines). $\mathrm{CO}_{2}-$ methylethanoate (a), $\mathrm{CO}_{2}$ - methyl-laurate (b), $\mathrm{CO}_{2}$ - methyl-myristate (c) $\mathrm{CO}_{2}$ - methyl-palmitate (d). The interaction parameters are available in Table 1. 


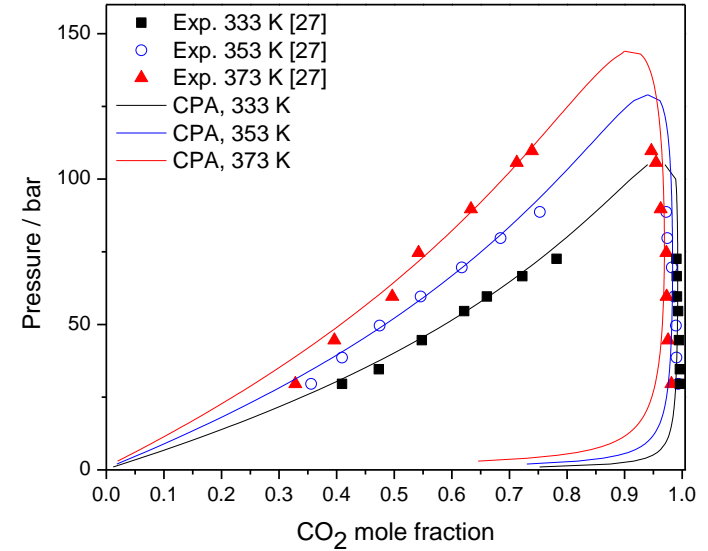

(a)

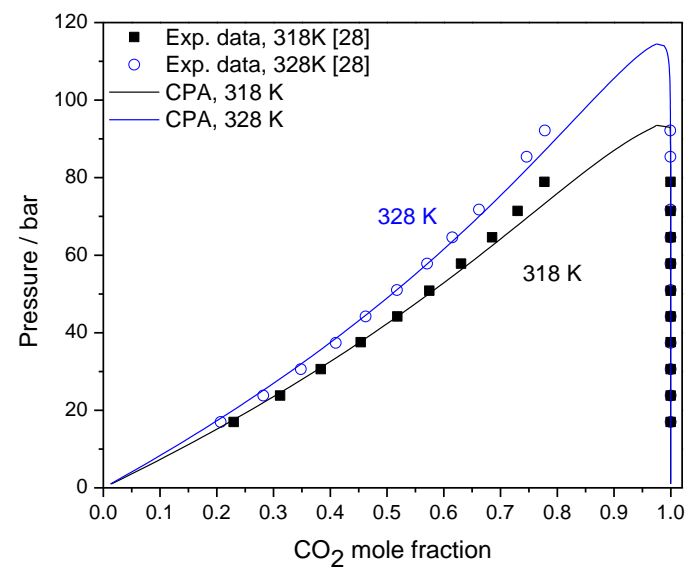

(c)

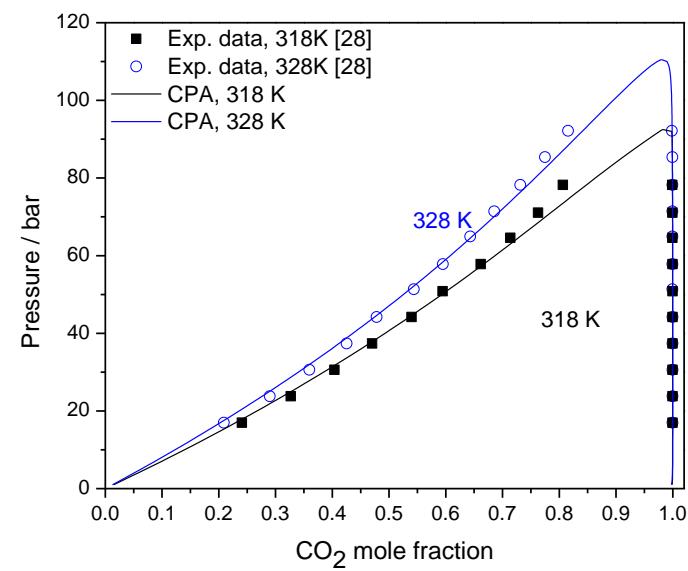

(b)

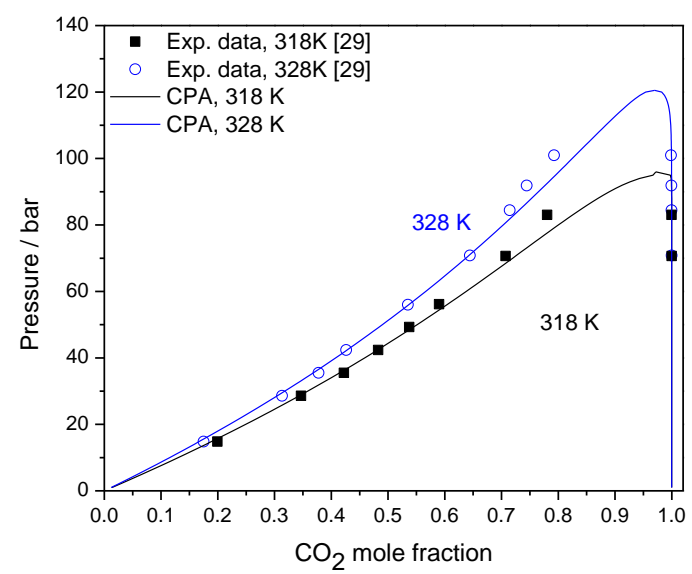

(d)

Figure 4. $\mathrm{CO}_{2}$ - ethyl- esters VLE. Experimental data (points) and CPA calculations (lines). $\mathrm{CO}_{2}$ - ethyl-propanoate (a), $\mathrm{CO}_{2}$ - ethyl-octanoate (b), $\mathrm{CO}_{2}$ - ethyl-decanoate (c) $\mathrm{CO}_{2}$ - ethyl-laurate (d). The interaction parameters are available in Table 1.

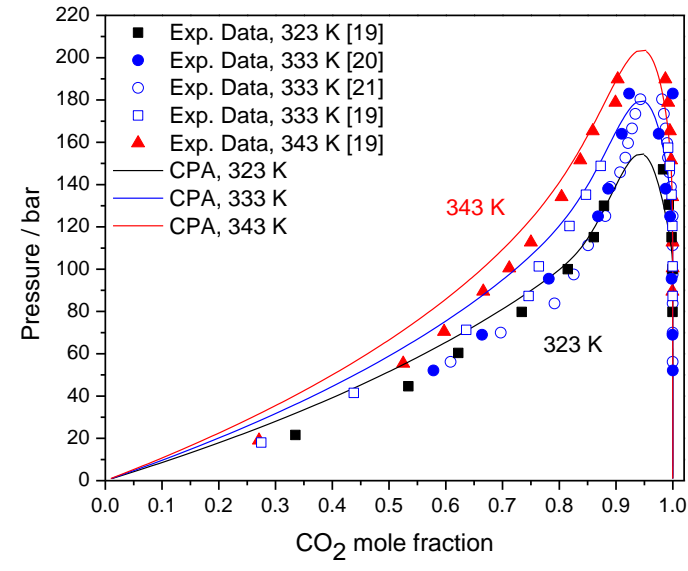

(a)

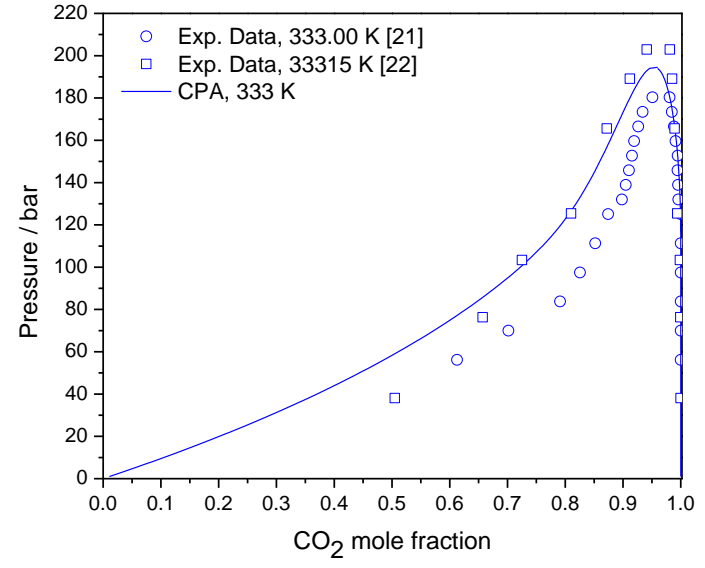

(b)

Figure 5. $\mathrm{CO}_{2}$ - methyl- esters of $\mathrm{C} 18-x$ fatty acids VLE. Experimental data (points) and CPA calculations (lines). $\mathrm{CO}_{2}$ - methyl-oleate (a) and $\mathrm{CO}_{2}$ - methyl-linoleate (b). The interaction parameters are available in Table 1. 


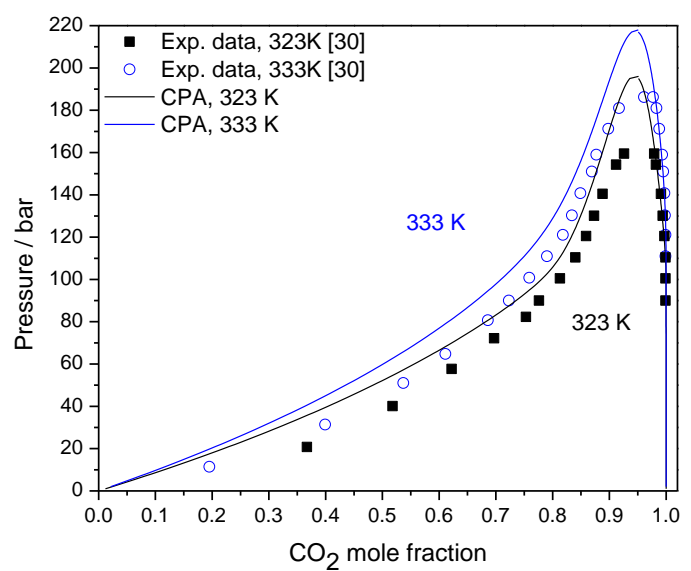

(a)

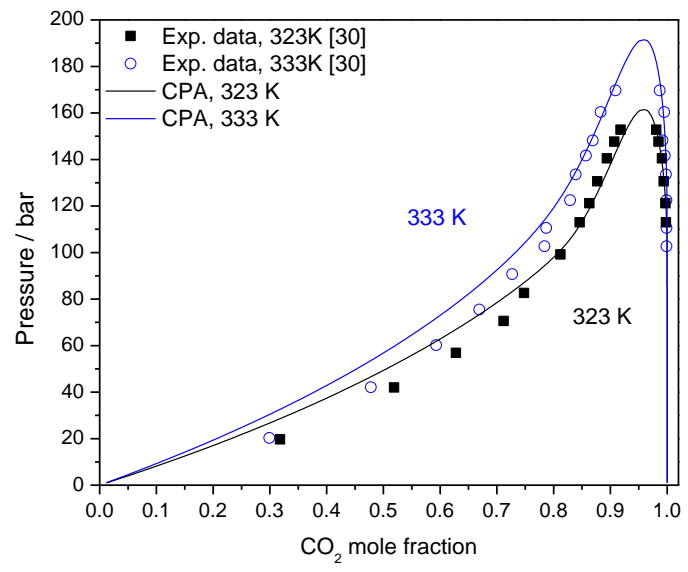

(c)

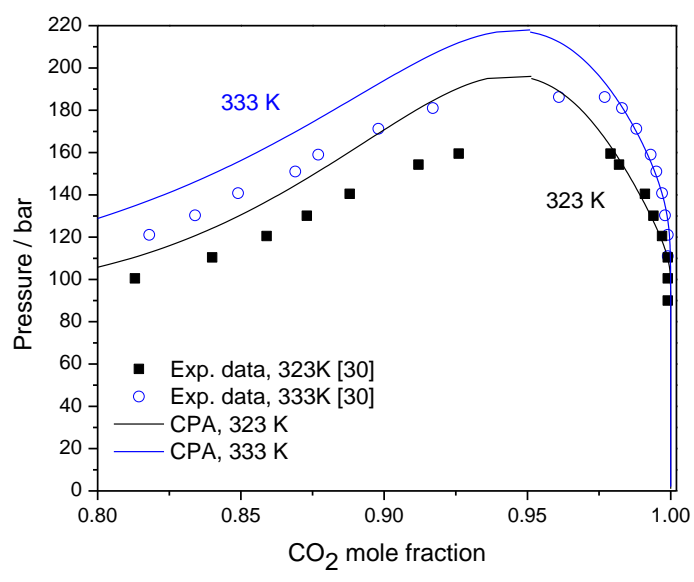

(b)

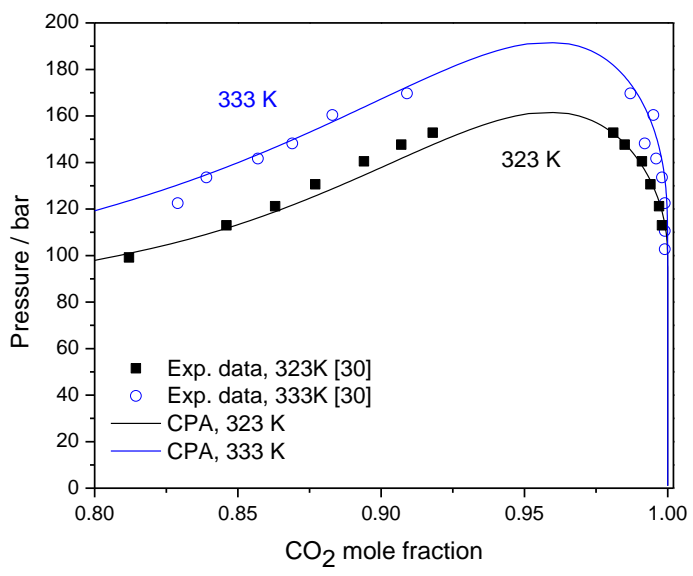

(d)

Figure 6. $\mathrm{CO}_{2}$ - ethyl- esters of C18-x fatty acids VLE. Experimental data (points) and CPA calculations (lines). $\mathrm{CO}_{2}$-ethyl-oleate ( $\mathrm{a}$ and $\mathrm{b}$ ) and $\mathrm{CO}_{2}$ - ethyl-linoleate (c and d). Interaction parameters of Table 1 were used.

The modeling of the VLE of binary systems containing $\mathrm{CO}_{2}$ and esters is usually performed with cubic equations of state [20, 21, 31-38]. In order to enhance the correlation ability of the cubic equations of state, more complicated mixing rules and EoS $/ G^{\mathrm{E}}$ models are used [34,35]. In this direction, the Huron-Vidal first-order (MHV1) and second-order (MHV2) mixing rules, as well as the LCVM method have been investigated by combining cubic equations of state with various activity coefficient models $[34,35]$.

In such approaches, attempts to use predictive models are of particular interest [32, 33, 38]. Jaubert and Coniglio suggested a purely predictive model, based on the PengRobinson equation of state. They have used a group contribution method to predict the binary interaction parameters and applied the model to predict the phase equilibria data of ternary and quaternary systems containing fatty acids and supercritical $\mathrm{CO}_{2}$ [33]. Furthermore, Jaubert and coworkers used a predictive version of the Peng - Robinson EoS (PPR78) to model $\mathrm{CO}_{2}$ - ethyl ester binary mixtures [38]. They conclude that the 
predictive ability of the model slightly deteriorates in the critical region of mixtures with high molecular weight esters.

In addition, Oliveira et al. [37], used the CPA equation of state to model the VLE of $\mathrm{CO}_{2}$ - ester binary mixtures. The authors considered seven binary systems and concluded that CPA can satisfactorily describe the phase behavior using one binary adjustable parameter. However, according to their approach, the critical region of $\mathrm{CO}_{2}$ mixtures with higher esters cannot be accurately described using $\mathrm{CO}_{2}$ pure fluid parameters adjusted to vapor pressure and density data (which overpredict the $\mathrm{CO}_{2}$ critical point) and, thus, the authors used the critical properties of $\mathrm{CO}_{2}\left(T_{c}, P_{c}\right.$ and acentric factor) in order to calculate the pure fluid parameters of this compound.

Furthermore, the VLE of $\mathrm{CO}_{2}$ with fatty acid methyl esters was modeled using a polar version of PC-SAFT [39]. Using a single binary adjustable parameter, the model satisfactorily describes the experimental data, but the description of the critical point region is not shown. In order to enhance the predicting ability of the approach, in a second step, the authors used a single binary parameter for all $\mathrm{CO}_{2}$ mixtures with fatty acid esters, without significantly compromising the performance of the model [39].

Finally, Haley and McCabe used a group contribution SAFT-VR (GC-SAFT-VR) model to predict the VLE of $\mathrm{CO}_{2}$ mixtures with methyl myristate, methyl oleate, methyl stearate, and methyl palmitate. Without using binary adjustable parameters (pure predictions), their model presented a satisfactory agreement with the experimental data away from the critical region, but resulted in an over prediction of the critical point, which is typical of all equations of state of this type [40].

Such observations are in agreement with the findings of this study, i.e. the CPA, using the pure fluid parameters of Tsivintzelis et al. [17], in many cases results in an overprediction of the critical region (see for example Figures 6a and 6b). However, it is well known that the CPA model, which unlike to other cubic equations does not use the experimental values of the critical properties for obtaining the pure fluid parameters, overpredicts the critical point of pure compounds and, as a consequence, present similar behavior for mixtures. This is a common limitation of many advanced models, such as the SAFT type models, and due to that many cross-over theories appeared in literature. In this direction, Llovell and Vega used a cross-over version of the soft SAFT EoS and modeled four $\mathrm{CO}_{2}$ - fatty acid ester binary mixtures using with two adjustable parameters per binary system [41].

\section{2 $\mathrm{CO}_{2}-$ Fatty acids}

Next the model was applied to describe the vapor - liquid equilibrium of $\mathrm{CO}_{2}$ - acid mixtures. All the $\mathrm{CO}_{2}$ - linear acid mixtures, for which experimental data were available in the literature, were investigated. However, as it was observed for $\mathrm{CO}_{2}-$ fatty acid ester mixtures, in some cases contradictory experimental data are found in literature, especially for higher acids. An example is shown in Figure 7. 


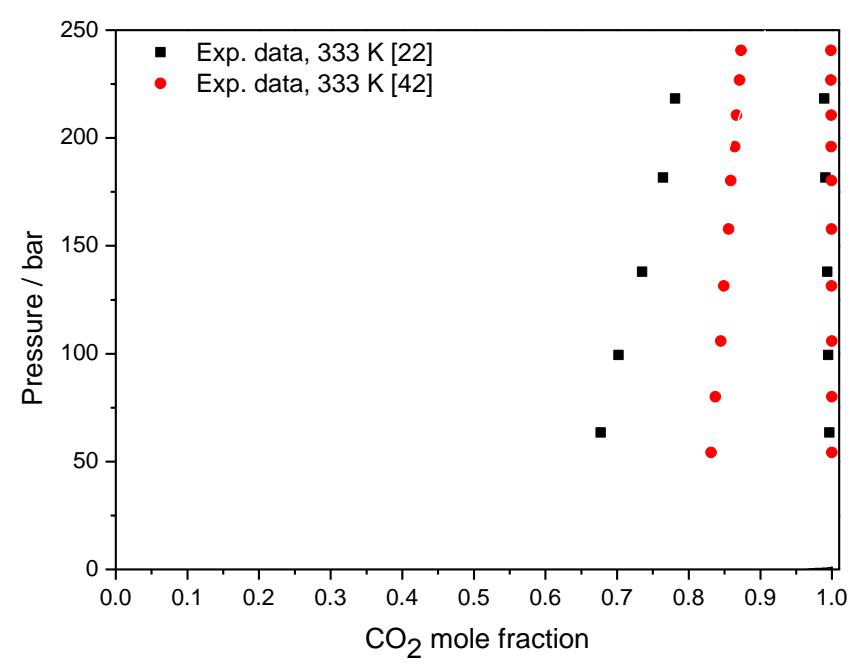

Figure 7. $\mathrm{CO}_{2}$ - linoleic acid VLE at $333 \mathrm{~K}$. Experimental data from literature $[22,42]$.

Table 2. Binary interaction parameters and deviations of model correlations from experimental data for $\mathrm{CO}_{2}(1)$ - Acid (2) systems.

\begin{tabular}{|c|c|c|c|c|c|c|}
\hline Acid & $\begin{array}{c}\text { Temp. } \\
\text { Range / K }\end{array}$ & $\boldsymbol{k}_{i j}$ & $\begin{array}{c}\% \mathbf{A A D}^{\mathrm{a}} \\
\text { in } \mathbf{x}_{1}\end{array}$ & $\begin{array}{c}\% \mathbf{A A D}^{\mathbf{a}} \\
{\text { in } \mathbf{y}_{1}}\end{array}$ & $\begin{array}{c}\% \mathbf{A A D}^{\mathbf{a}} \\
\text { in } \mathbf{y}_{2}\end{array}$ & References \\
\hline Acetic Acid $(C 2: 0)$ & $333-353$ & 0.0190 & 4.3 & 1.3 & 5.9 & [43] \\
\hline Butanoic Acid (C4:0) & $333-393$ & -0.0220 & 13.4 & 2.7 & 71 & [44] \\
\hline Pentanoic Acid (C5:0) & $333-393$ & -0.0318 & 13.0 & 3.4 & 80 & [44] \\
\hline Hexanoic Acid (C6:0) & $328-373$ & -0.0220 & 9.6 & 0.8 & 73 & {$[44,45]$} \\
\hline Octanoic Acid $(C 8: 0)$ & $328-373$ & -0.0030 & 4.8 & 0.8 & 55 & {$[44]$} \\
\hline Decanoic Acid (C10:0) & $323-353$ & 0.0200 & 6.9 & - & - & [46] \\
\hline Lauric Acid (C12:0) & $333-353$ & 0.0380 & 2.6 & 0.2 & 44 & [45] \\
\hline Palmitic Acid (C16:0) & $353-373$ & 0.0820 & 7.3 & 0.1 & 39 & [45] \\
\hline Oleic Acid (C18:1) & $323-333$ & 0.0641 & 12.9 & 0.3 & 56 & {$[22,25]$} \\
\hline Linoleic Acid (C18:2) & 333 & 0.0500 & 11.4 & 0.4 & $>100$ & {$[22,42]$} \\
\hline
\end{tabular}

a\%AAD $=\frac{1}{n} \sum_{i}\left|\frac{X_{i}^{c a l}-X_{i}^{\exp }}{X_{i}^{\exp }}\right| \times 100$ where $X$ stands for the $\mathrm{CO}_{2}$ mole fraction on the liquid phase $\left(x_{1}\right)$ and the acid mole fraction $\left(y_{2}\right)$ in the vapor phase, while $n$ is the number of experimental data points

Hydrogen bonding interactions were accounted for carboxylic acids. All acids were modeled using the $1 \mathrm{~A}$ association scheme, which is a very popular association scheme in the SAFT type models to account the possible dimerization of carboxylic acids, using the parameters reported by Tsivintzelis et al [17]. The vapor - liquid equilibrium of $\mathrm{CO}_{2}$ - acid mixtures was modeled assuming that $\mathrm{CO}_{2}$ is an inert compound. Thus, no cross association interactions (of electron donor-acceptor type) were assumed between $\mathrm{CO}_{2}$ and acid molecules, although such interactions may occur, especially for mixtures with low molecular weight acids. However, because the aim of this study is to model systems with high molecular weight acids (compounds relevant to biodiesel production) and since the CPA rather satisfactorily describes such mixtures using only one adjustable parameter, cross interactions were not accounted for. All acids were modeled using the $1 \mathrm{~A}$ association scheme and the parameters are given by Tsivintzelis 
et al [17]. All the $\mathrm{CO}_{2}$ - linear acid mixtures, for which experimental data were available in the literature, were investigated and the results are presented in Table 2.

In Figure 8a, the binary interaction parameters of Table 2 are plotted against the number of carbon atoms in acid molecules. It is shown that the $k_{i j}$ s follow a linear trend for acids with more than four carbon atoms. For acids with less than four carbon atoms, the correlation shown in Figure 8a cannot be used and this happens, probably, due to the peculiar hydrogen bonding interactions in such systems. We have seen such behavior for many homologous series, see for example ester-alcohol systems in reference [17], and with many models. In Figure $8 \mathrm{~b}$, the $k_{i j} \mathrm{~s}$ are plotted against the number of double bonds for C18- $x$ fatty acids. As it was also observed for the esters of C18- $x$ fatty acids, the binary interaction parameter becomes lower as the number of double bonds increases.

The results are illustrated in Figures 9 and 10. In most cases, the model satisfactorily describes the experimental data. For mixtures with C4:0, C5:0 and C6:0 acids, the model significantly overestimates the mixtures' critical point, however, the results are better for mixtures with $\mathrm{C} 8: 0, \mathrm{C} 10: 0$ and $\mathrm{C} 12: 0$ acids.

Oliveira et al. also modeled the VLE of binary systems containing $\mathrm{CO}_{2}$ with propanoic acid, hexanoic acid, octanoic acid or oleic acid and concluded that the CPA can satisfactorily describe the phase behavior using one binary adjustable parameter [37]. Byun et al. used the SAFT EoS and the PR EoS to model the VLE of binary mixtures containing $\mathrm{CO}_{2}$ and organic acids with up to eight carbon atoms [44]. They conclude that the SAFT EoS satisfactorily predicts the phase behavior of the studied mixtures using two temperature independent adjustable parameters.

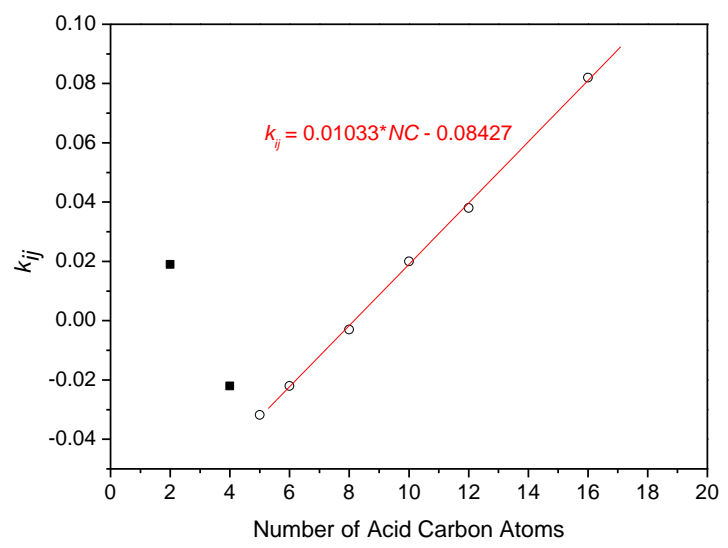

(a)

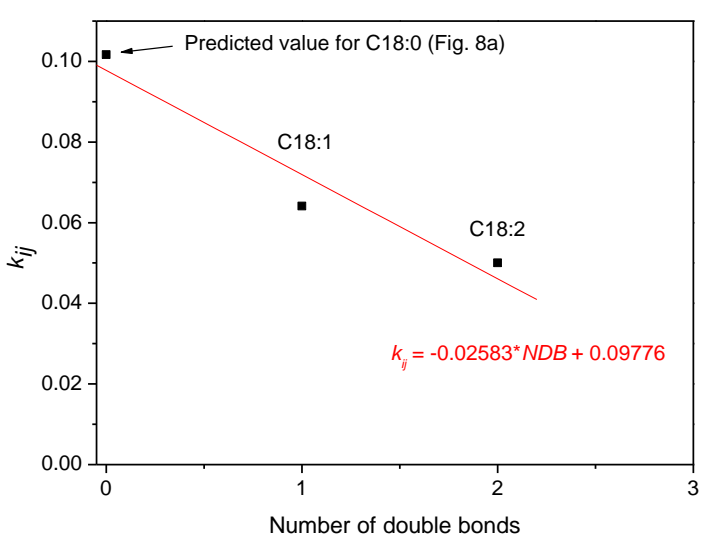

(b)

Figure 8. Binary interaction parameters $\left(k_{i j} \mathrm{~s}\right)$ against the number of acid carbon atoms (left) and against the number of double bonds for C18- $x$ fatty acids (stearic acid (C18:0), oleic acid (C18:1) and linoleic acid (C18:2)) (right). 


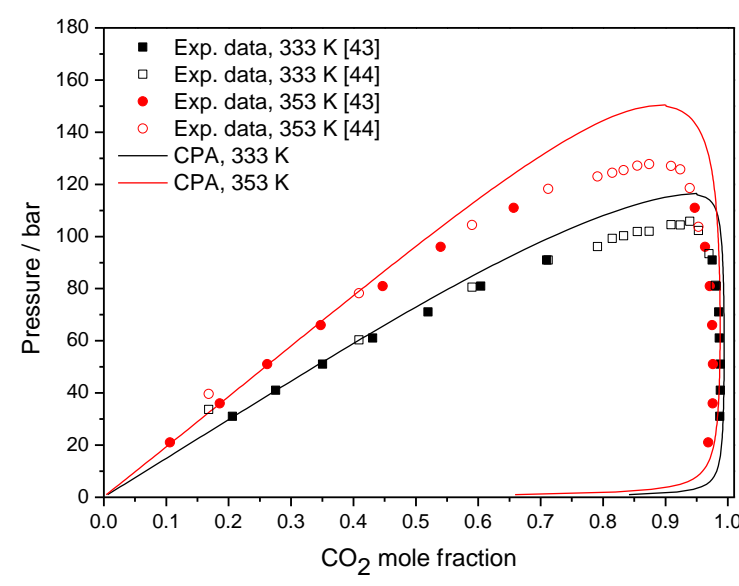

(a)

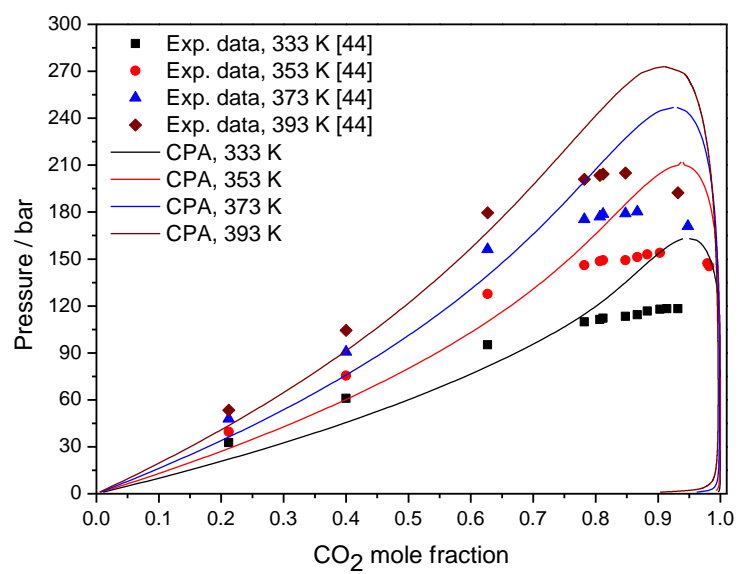

(c)

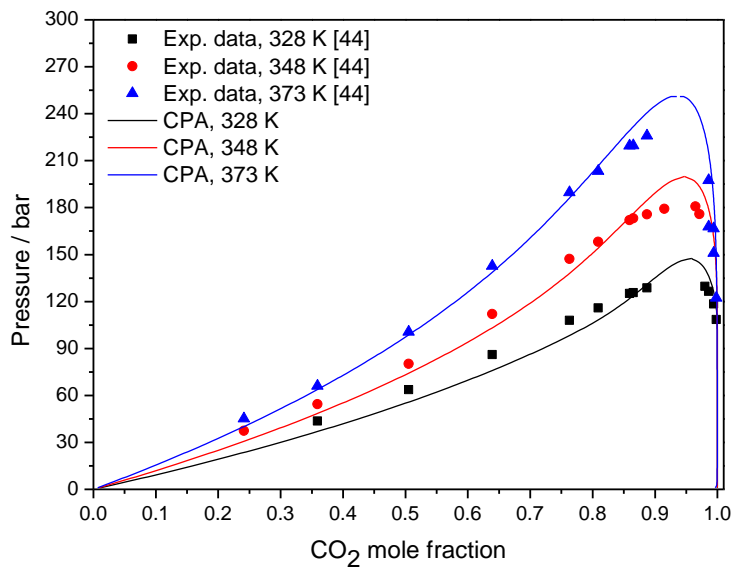

(e)

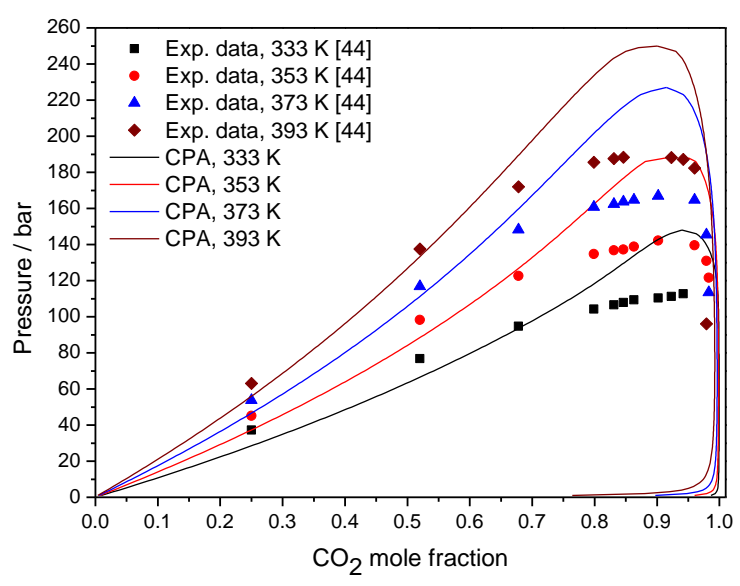

(b)

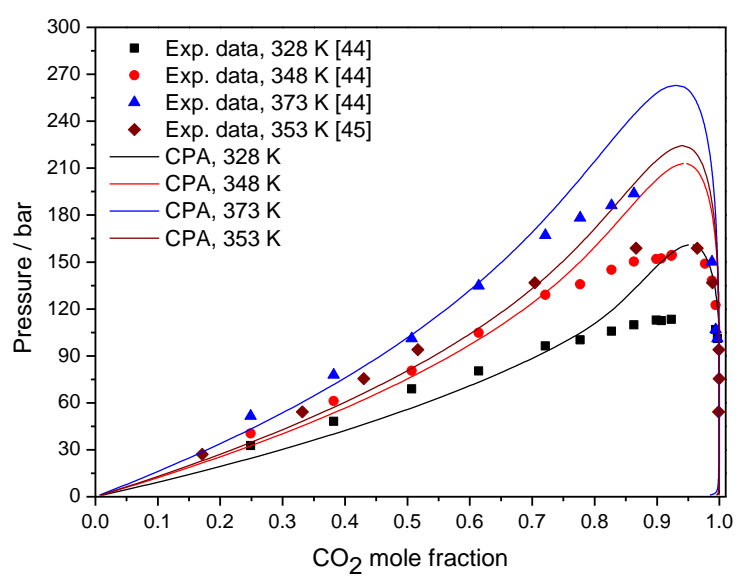

(d)

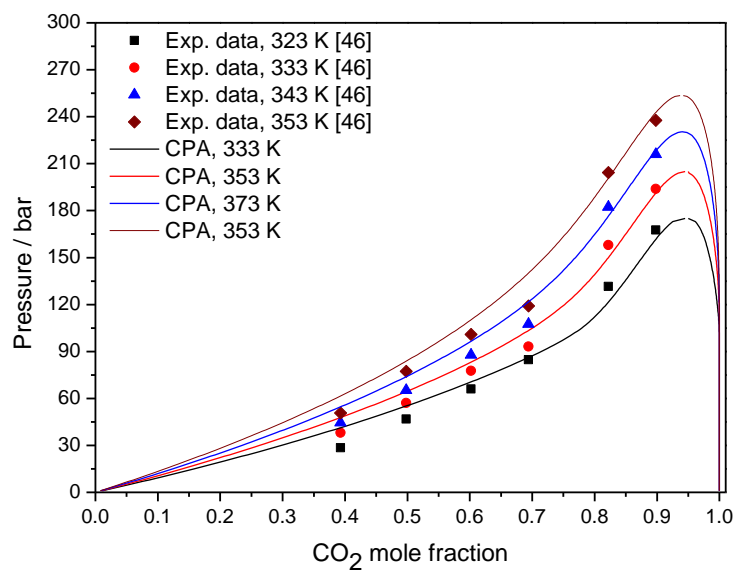

(f)

Figure 9. $\mathrm{CO}_{2}$ - fatty acids VLE. Experimental data (points) and CPA calculations (lines). Binary mixtures of $\mathrm{CO}_{2}$ with acetic acid (a), butanoic acid (b), pentanoic acid (c), hexanoic acid (d), octanoic acid (e), decanoic acid (f). The interaction parameters are available in Table 2. 


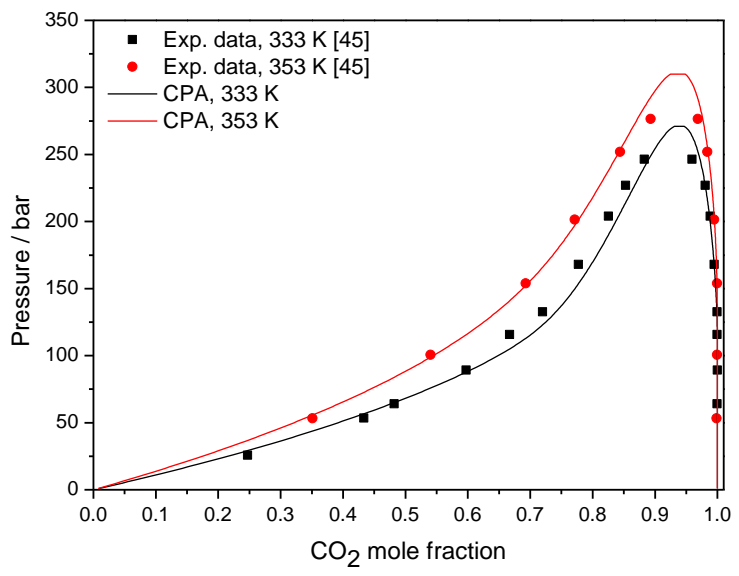

(a)

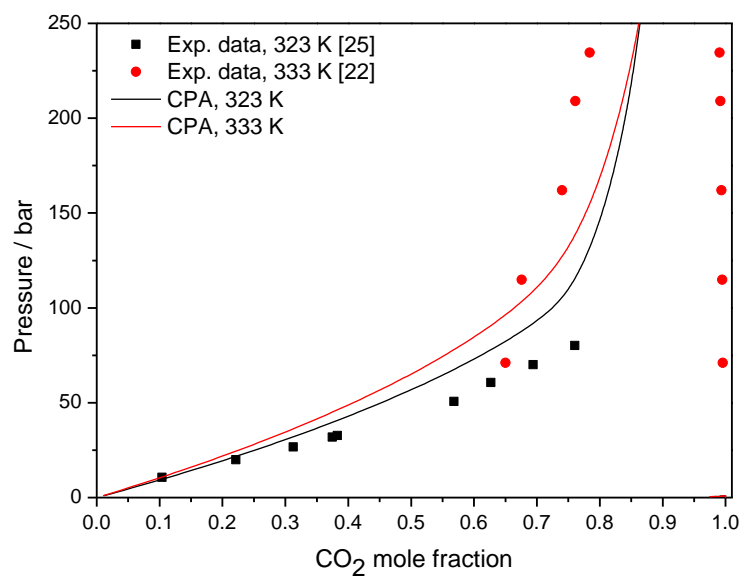

(c)

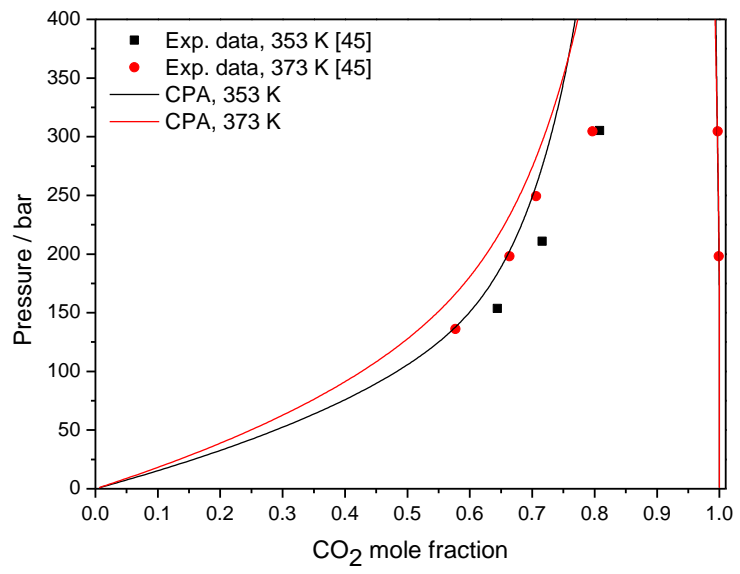

(b)

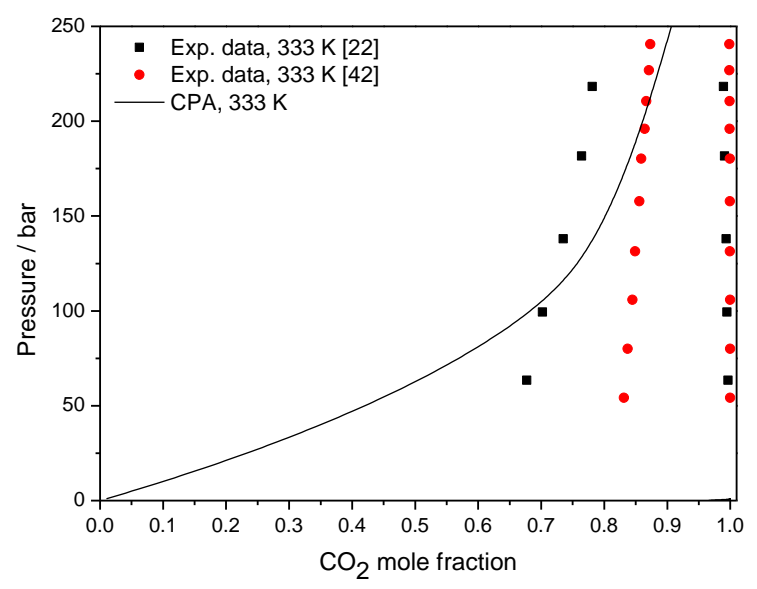

(d)

Figure 10. $\mathrm{CO}_{2}$ - fatty acids VLE. Experimental data (points) and CPA calculations (lines). Binary mixtures of $\mathrm{CO}_{2}$ with lauric acid (a), palmitic acid (b), oleic acid (c) and linoleic acid (d). The interaction parameters are available in Table 2.

\section{Ternary and multicomponent mixtures}

Next the model was applied to predict the phase behavior of ternary and multicomponent mixtures containing $\mathrm{CO}_{2}$ with fatty acids or esters of fatty acids. In all cases no parameters were adjusted to ternary systems' data and all binary parameters were adopted from the corresponding sub-binary systems. Consequently, the results presented in this section are pure predictions.

Initially, a ternary mixture that contains $\mathrm{CO}_{2}$ with two saturated fatty acid esters (methyl myristate and methyl palmitate) was modeled using the data of Lockemann [25]. As it is observed in Figure 11, the experimental data are scattered, similarly to the majority of experimental data for such systems, as discussed in section 2.1. The vapor - liquid equilibrium of such system was modeled using pure fluid parameters from literature $[17,18]$ and the binary parameters of Table 1 . The methyl myristate - methyl 
palmitate binary interaction parameter was set equal to zero, which is reasonable, since such compounds present very similar molecular structure. In all cases flash calculations were performed using as feed compositions the center of the experimental tie lines. The results are presented in Figure 11 and in Table 3. The CPA model predicts the liquid phase compositions with reasonable accuracy. However, in both investigated pressures, it underestimates the $\mathrm{CO}_{2}$ content of the liquid phase, following the behavior observed in Figure 3, i.e the model slightly underestimates the $\mathrm{CO}_{2}$ content of the liquid phase of the corresponding sub-binary mixtures at $323 \mathrm{~K}$. Moreover, the model presents better agreement with the experimental data at 110 bar, than at 70 bar. The vapor phase contains very small amounts of fatty acid esters. According to the experimental data [25], the mole fractions of esters are in the order of $10^{-4}$ at $323 \mathrm{~K}$ and 70 bar and $10^{-3}$ at $323 \mathrm{~K}$ and 110 bar. The model underpredicts, approximately one order of magnitude, the ester composition of the vapor phase at 70 bar. However, as shown in Table 3, results are significantly more accurate for 110 bar.

Table 3. Deviations ${ }^{\text {a }}$ from experimental data for ternary systems.

\begin{tabular}{|l|l|l|l|l|l|l|l|}
\hline $\begin{array}{c}\text { Temp. / } \\
\mathrm{K}\end{array}$ & $\begin{array}{c}\text { Pressure } \\
/ \text { bar }\end{array}$ & $\begin{array}{c}\text { AAD in } \\
\mathrm{x}_{1}\end{array}$ & $\begin{array}{c}\text { AAD in } \\
\mathrm{x}_{2}\end{array}$ & $\begin{array}{c}\text { AAD in } \\
\mathrm{x}_{3}\end{array}$ & $\begin{array}{c}\text { AAD in } \\
\mathrm{y}_{1}\end{array}$ & $\begin{array}{c}\text { AAD in } \\
\mathrm{y}_{2}\end{array}$ & $\begin{array}{c}\text { AAD in } \\
\mathrm{y}_{3}\end{array}$ \\
\hline $\mathrm{CO}_{2}(1)$ - methyl myristate (2) - methyl palmitate (3) \\
\hline 323 & 70 & 7.6 & 15 & 19 & 0.1 & 86 & 98 \\
\hline 323 & 110 & 2.2 & 15 & 21 & 0.3 & 23 & 31 \\
\hline $\mathrm{CO}_{2}(1)$ - methyl oleate (2) - methyl linolate (3) \\
\hline 333 & $\sim 148$ & 2.2 & 81 & 81 & 0.4 & 37 & 38 \\
\hline
\end{tabular}

a\%AAD $=\frac{1}{n} \sum_{i}\left|\frac{X_{i}^{c a l}-X_{i}^{\exp }}{X_{i}^{\exp }}\right| \times 100$ where $X$ stands for mole fraction of the liquid phase $\left(x_{i}\right)$ or the vapor phase $\left(y_{i}\right)$, while $n$ is the number of experimental data points

Next, the model was applied to predict the vapor - liquid equilibrium of a ternary mixture containing $\mathrm{CO}_{2}$ and two unsaturated fatty acid esters (methyl oleate and methyl linoleate). The calculated results were compared to the experimental data [47] in Figure 12. Similarly to the previous system, the model slightly underestimates the $\mathrm{CO}_{2}$ content of the liquid phase, which is a behavior that arises from the corresponding sub-binary mixtures (see Figure 5). As shown in Table 3, the model predicts the very small fraction of esters in the vapor phase (of the order of $10^{-3}$, according to the experimental data [41]) with reasonable accuracy. 


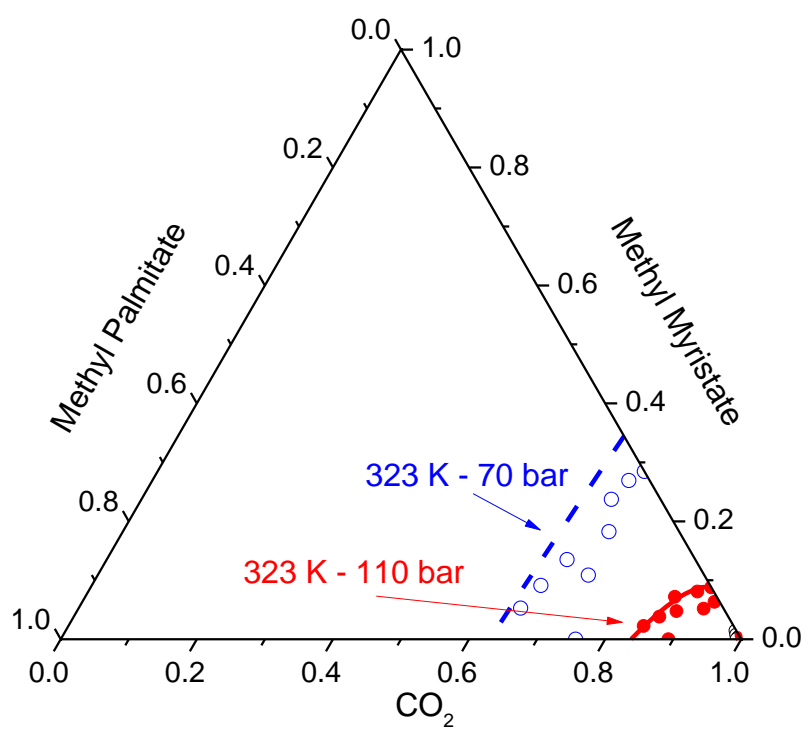

Figure 11. $\mathrm{CO}_{2}$ methyl myristate - methyl palmitate VLE at $323 \mathrm{~K}$. Experimental data [25] for 70 bar (open symbols) and 110 bar (solid symbols), as well as CPA correlations (lines).

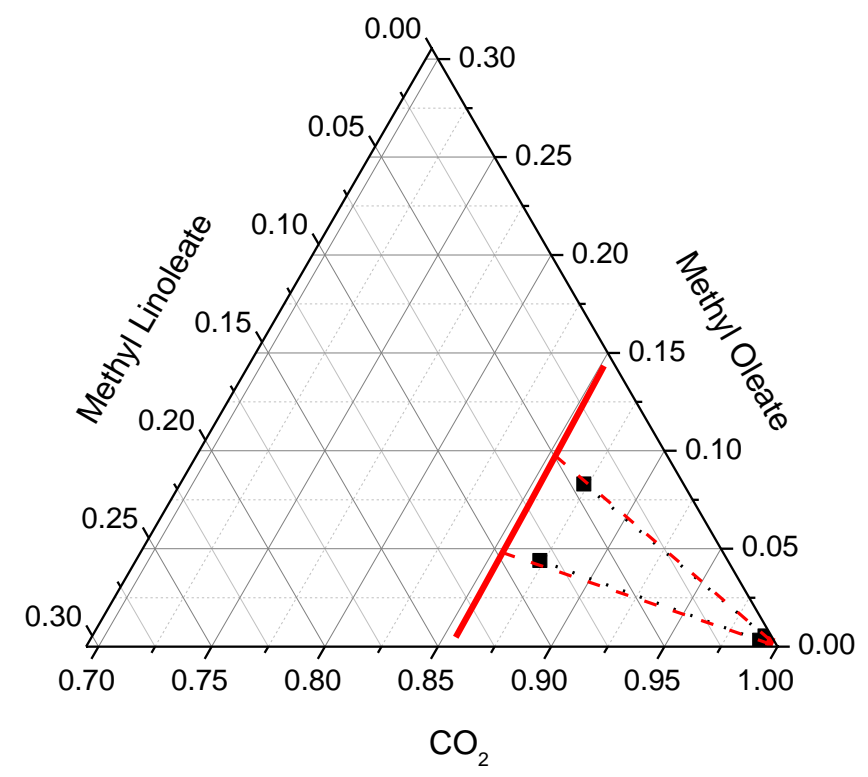

Figure 12. $\mathrm{CO}_{2}$ - methyl oleate - methyl linoleate VLE at $333 \mathrm{~K}$ and approximately 148 bar. Experimental data [47] (symbols) and CPA correlations (solid lines). The experimental tie lines (black dot line) and the calculated tie lines (red dash lines) are also shown.

Next, the model was applied to predict the phase behavior of a ternary system that contains $\mathrm{CO}_{2}$ with methanol and lauric acid, which is a reactive mixture, rendering the 
modeling of the phase behavior a challenging task. Such system was experimentally investigated by Ferreira et al. [48], who report vapor - liquid - liquid (VLLE), liquidliquid (LLE) and vapor-liquid (VLE) equilibrium data for various mixture compositions. The model was applied using binary parameters adopted from the subbinary mixtures. In more detail, for $\mathrm{CO}_{2}$ - lauric acid, the binary interaction parameter of this study was used. For $\mathrm{CO}_{2}-$ methanol, cross association interactions were accounted for assuming one positive and one negative association sites on $\mathrm{CO}_{2}$ and using an experimental value for the association energy [18]. Binary parameters for $\mathrm{CO}_{2}$ - methanol were adopted from Tsivintzelis et al. [18]. In absence of binary parameters for the sub-binary methanol - lauric acid system, the model was applied using the parameters for the methanol - methyl laurate [17]. Results for two representative systems are presented in Figures 13 and 14. Ferreira et al. used two binary parameters per sub-binary system (in total six parameters, while the parameters for the methanol - lauric acid were adjusted to the ternary system's data) in order to model the ternary mixture with the Peng-Robinson EoS [48]. According to their results, the VLE data are accurately correlated, while the VLLE is qualitatively described.

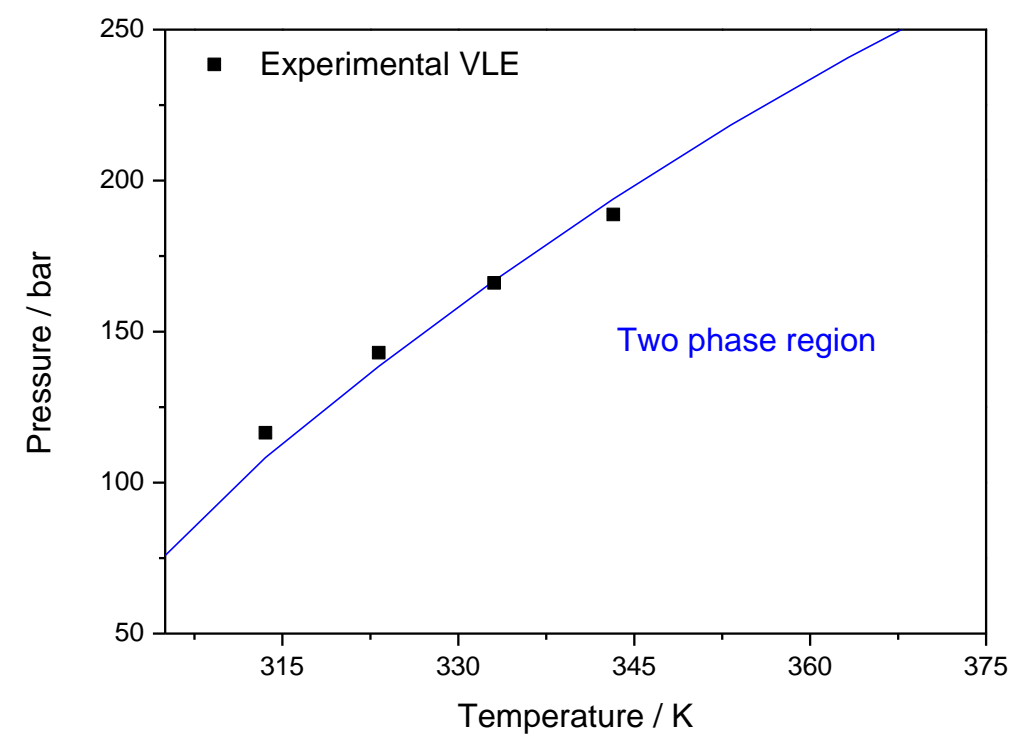

Figure 13. VLE of $\mathrm{CO}_{2}$ - methanol - lauric acid system. Experimental data (points [48], for a mixture containing $\mathrm{CO}_{2}: 85.90 \%$ mol, methanol: $9.40 \% \mathrm{~mol}$ and lauric acid $4.7 \% \mathrm{~mol}$ ) and CPA predictions (lines). 


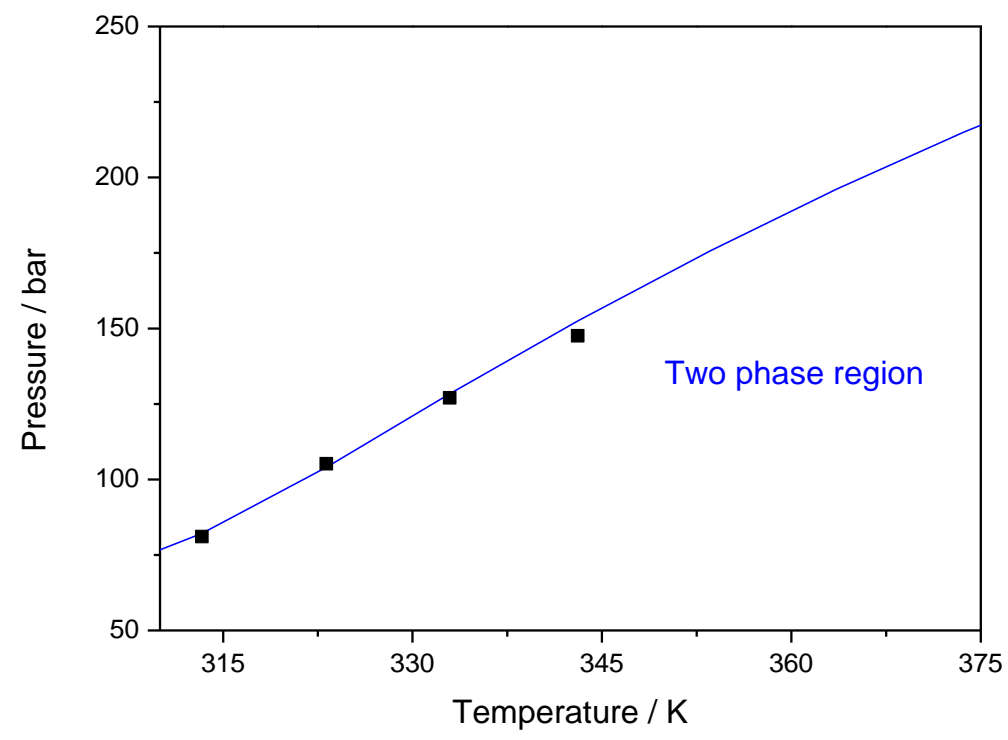

Figure 14. VLE of $\mathrm{CO}_{2}$ - methanol - lauric acid system. Experimental data (points [48], for a mixture containing $\mathrm{CO}_{2}: 74.74 \% \mathrm{~mol}$, methanol: $21.05 \% \mathrm{~mol}$ and lauric acid $4.21 \% \mathrm{~mol}$ ) and CPA predictions (lines).

Finally, the model was applied to predict the phase behavior of a multicomponent mixture containing $\mathrm{CO}_{2}$ and a real biodiesel sample. The experimental data were taken from Pinto et al. [49]. Biodiesel was considered as a mixture of methyl esters of fatty acids (C16:0, C18:0, C18:1, C18:2, C18:3), according to the analysis performed by the authors. In all cases the binary interaction parameters of $\mathrm{CO}_{2}$ with the various fatty acid esters were adopted from Table 1, while binary interaction parameters between fatty acids were set equal to zero, which is reasonable, since such compounds have very similar molecular structure. The deviations of model predictions from the experimental data are presented in Table 4, while results are illustrated in Figure 15.

Table 4. Deviations ${ }^{\text {a }}$ from experimental data [49] for $\mathrm{CO}_{2}$ - biodiesel multicomponent system.

\begin{tabular}{l|c|c|c|}
\hline Temperature / K & $\mathrm{AAD}^{\mathrm{a}}$ in $\mathrm{x}_{\mathrm{CO} 2}$ & $\mathrm{AAD}^{\mathrm{a}}$ in $\mathrm{yCO}$ & $\mathrm{AAD}^{\mathrm{a}}$ in yester \\
\hline 323.15 & 6.6 & 0.4 & 39 \\
\hline 333.15 & 6.7 & 0.3 & 25 \\
\hline 343.15 & 7.2 & 0.5 & 24 \\
\hline
\end{tabular}
a\%AAD $=\frac{1}{n} \sum_{i}\left|\frac{X_{i}^{\text {cal }}-X_{i}^{\text {exp }}}{X_{i}^{\exp }}\right| \times 100$ where $X$ stands for mole fraction of the liquid phase $\left(x_{i}\right)$ or the vapor
phase $\left(y_{i}\right)$, while $n$ is the number of experimental data points

phase $\left(y_{i}\right)$, while $n$ is the number of experimental data points 


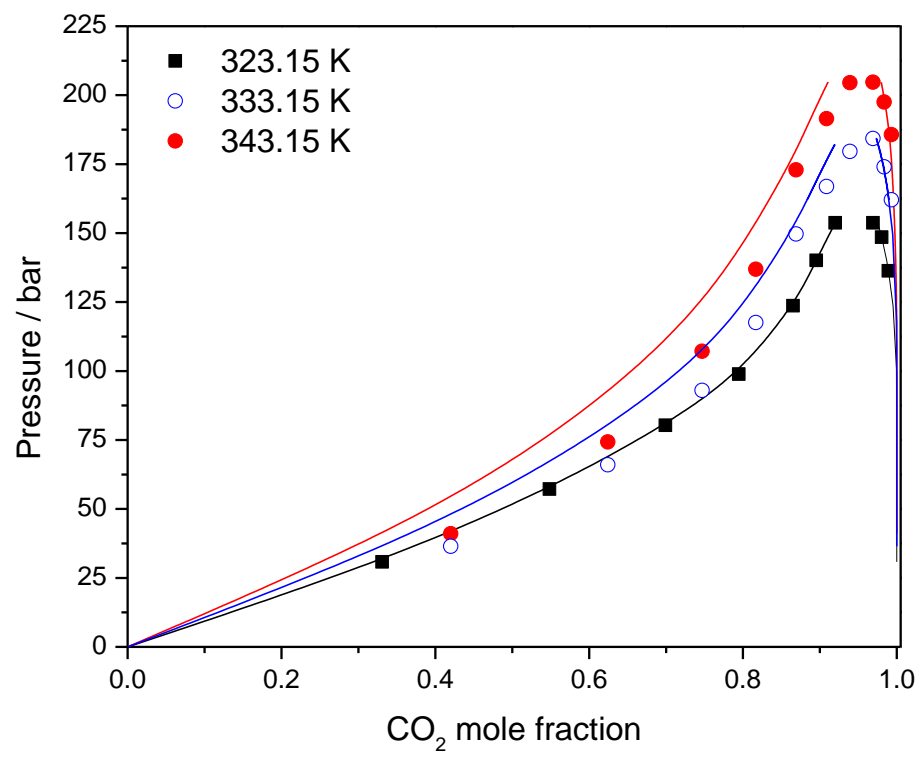

Figure 15. Phase behavior of $\mathrm{CO}_{2}$ - biodiesel system. Experimental data (points, [49]) and CPA predictions (lines).

\section{Conclusions}

In this study, the application of the CPA equation of state to $\mathrm{CO}_{2}-$ ester and $\mathrm{CO}_{2}-$ fatty acid systems was investigated. The model, using one temperature independent binary interaction parameter, rather satisfactorily describes the phase behavior of the investigated $\mathrm{CO}_{2}$ systems, however overpredicts the mixtures' critical point. In such systems, correlations of the binary interaction parameter with the number of esters' carbon atoms, or, where it was possible, with the number of double bonds for esters or fatty acids with the same number of carbon atoms, were obtained. In order to further test the predictive ability of the model coupled with the modeling approaches described here, as well as in our previous studies $[17,18]$, the CPA equation of state was applied to predict the phase behavior of three ternary mixtures. All the binary parameters were adopted from the corresponding sub-binary mixtures and, overall, satisfactory predictions were obtained.

This study is a continuation of our previous study in modeling mixtures relevant to the biodiesel production [17]. In such study, all the most important mixtures in biodiesel processes were investigated and pure fluid and binary parameters were obtained. In addition, correlations for predicting the pure and binary parameters in cases of lack of experimental data were developed. In this way, the predictive ability of the model is enhanced and the application of the CPA model to real systems relevant to biodiesel production becomes more feasible.

\section{Acknowledgements}

The authors wish to thank BP International Limited (UK), Equinor (Norway), and Petrobras (Brazil) for supporting this work as part of the CHIGP project (Chemicals in 
Gas Processing). We wish to thank particularly BP for input and many exciting discussions.

\section{References}

[1] F. Temelli, Perspectives on supercritical fluid processing of fats and oils, J. of Supercritical Fluids 47 (2009) 583-590.

[2] J. Macaira, A. Santana, A. Costa, E. Ramirez, M.A. Larroyoz, Process intensification using $\mathrm{CO}_{2}$ as a cosolvent under supercritical conditions applied to design of biodiesel production, Ind. Eng. Chem. Res. 53 (2014) 3985-3995.

[3] L. Soh, J. Curry, E.J. Beckman, J.B. Zimmerman, Effect of system conditions for biodiesel production via transesterification using carbon dioxide - methanol mixtures in the presence of a heterogeneous catalyst, ACS Sustain. Chem. Eng. 2 (2013) 387-395.

[4] C. Silva, L. Soh, A. Barbeiro, J. Zimmerman, W. D. Seider, Phase equilibria of triolein to biodiesel reactor systems, Fluid Phase Equilib. 409 (2016) 171-192.

[5] O.A.S. Araújo, F.R. Silva, L.P. Ramos, M.K. Lenzi, P.M. Ndiaye, M.L. Corazza, Phase behaviour measurements for the system (carbon dioxide + biodiesel +ethanol) at high pressures, J. Chem. Thermodyn. 47 (2012) 412-419.

[6] G.M. Kontogeorgis, E. Voutsas, I. Yakoumis, D.P. Tassios, An equation of state for associating fluids, Ind. Eng. Chem. Res. 35 (1996) 4310-4318.

[7] M.S. Wertheim, Fluids with Highly Directional Attractive Forces. 1. Statistical Thermodynamics, J. Stat. Phys. 35 (1984) 19-34.

[8] M.S. Wertheim, Fluids with Highly Directional Attractive Forces. 2. Thermodynamic Perturbation-Theory and Integral-Equations, J. Stat. Phys. 35 (1984) 35-47.

[9] M.S. Wertheim, Fluids with Highly Directional Attractive Forces. 3. Multiple Attraction Sites, J. Stat. Phys. 42 (1986) 459-476.

[10] M.S. Wertheim, Fluids with Highly Directional Attractive Forces. 4. Equilibrium Polymerization, J. Stat. Phys. 42 (1986) 477-492.

[11] I. Economou, Statistical associating fluid theory: A successful model for the calculation of thermodynamic and phase equilibrium properties of complex fluid mixtures, Ind. Eng. Chem. Res. 41 (2002) 953-962.

[12] G.M. Kontogeorgis, M.L. Michelsen, G.K. Folas, S. Derawi, N. Von Solms, E.H. Stenby, Ten years with the CPA (Cubic-Plus-Association) equation of state. Part 1. Pure compounds and self-associating systems, Ind. Eng. Chem. Res. 45 (2006) 4855-4868.

[13] G.M. Kontogeorgis, M.L. Michelsen, G.K. Folas, S. Derawi, N. Von Solms, E.H. Stenby, Ten years with the CPA (Cubic-Plus-Association) equation of state. Part 2. Cross-associating and multicomponent systems, Ind. Eng. Chem. Res. 45 (2006) 4869-4878.

[14] G.M. Kontogeorgis, I.G. Economou, Equations of state: From the ideas of van der Waals to association theories, J. Superitical Fluids, 55 (2010) 421-437.

[15] G.M. Kontogeorgis, G.K. Folas, Thermodynamic models for industrial applications. From classical and advanced mixing rules to association theories, first ed., John Wiley and Sons, 2010. 
[16] J-Ch. de Hemptinne, J-M. Ledanois, P. Mougin, A. Barreau, Select Thermodynamic models for process simulation. A practical guide using a three steps methodology, first ed., Editions Technip, 2012.

[17] I. Tsivintzelis, S. Ali, G.M. Kontogeorgis, Modeling systems relevant to the biodiesel production using the CPA equation of state, Fluid Phase Equilibr. 430 (2016) 75-92.

[18] I. Tsivintzelis, G.M. Kontogeorgis, M.L. Michelsen, E.H. Stenby, Modeling phase equilibria for acid gas mixtures using the CPA equation of state. Part II: Binary mixtures with $\mathrm{CO}_{2}$, Fluid Phase Equilibr. 306 (2011) 38-56.

[19] H. Inomata, T. Kondo, S. Hiroyama, K. Arai, Y. Suzuki, M. Konno, Vapour-liquid equilibria for binary mixtures of carbon dioxide and fatty acid methyl esters, Fluid Phase Equilibr. 46 (1989) 41-52.

[20] T. Fang, M. Goto, Z. Yun, X.-L. Ding, T. Hirose, Phase equilibria for binary systems of methyl oleate-supercritical $\mathrm{CO}_{2}$ and $\alpha$-tocopherol-supercritical $\mathrm{CO}_{2}$, J. Supercritical Fluids, 30 (2004) 1-16.

[21] C.-M.J. Chang, M.-S. Lee, B.-C. Li, P.-Y. Chen, Vapor-liquid equilibria and densities of $\mathrm{CO}_{2}$ with four unsaturated fatty acid esters at elevated pressures, Fluid Phase Equilibr. 233 (2005) $56-65$.

[22] M. Zou, Z.R. Yu, P. Kashulines, S.S.H. Rizvi, J.A. Zollweg, Fluid-liquid phase equilibria of fatty acids and fatty acid methyl esters in supercritical carbon dioxide, J. Supercritical Fluids, 3 (1990) 23-28.

[23] K. Ohgaki; T. Katayama, Isothermal vapor-liquid equilibriums for systems ethyl ether-carbon dioxide and methyl acetate-carbon dioxide at high pressures, J. Chem. Eng. Data 20 (1975) 264-267.

[24] C.A. Lockemann, S. Munoz de Soto-Soliz, E.-U. Schlunder, High-pressure phase equilibria and densities of the binary system carbon dioxide/methyl laurate, Chem. Eng. Process. 34 (1995) 551-564.

[25] C.A. Lockemann, High-pressure phase equilibria and densities of the binary mixtures carbon dioxide-oleic acid, carbon dioxide-methyl myristate, and carbon dioxide-methyl palmitate and of the ternary mixture carbon dioxide-methyl myristate-methyl palmitate, Chem. Eng. Process. 33 (1994) 171- 187.

[26] Z. Wagner, J. Pavlíček, Vapour-liquid equilibrium in the carbon dioxide-ethyl acetate system at high pressure, Fluid Phase Equilibr. 97 (1994) 119-126.

[27] Y.-L. Tian, H.-G. Zhu, Y. Xue, Z.-H. Liu, L. Yin, Vapor-liquid equilibria of the carbon dioxide + ethyl propanoate and carbon dioxide + ethyl acetate systems at pressure from 2.96 MPa to $11.79 \mathrm{MPa}$ and temperature from $313 \mathrm{~K}$ to $393 \mathrm{~K}$, J. Chem. Eng. Data, 49 (2004) 1554-1559.

[28] W.-H. Hwu, J.-S. Cheng, K.-W. Cheng, Y.-P. Chen, Vapor-liquid equilibrium of carbon dioxide with ethyl caproate, ethyl caprylate and ethyl caprate at elevated pressures, J. Supercritical Fluids, 28 (2004) 1-9.

[29] K.-W. Cheng, M. Tang, Y.P. Chen, Vapor-liquid equilibria of carbon dioxide with diethyl oxalate, ethyl laurate, and dibutyl phthalate binary mixtures at elevated pressures, Fluid Phase Equilibr. 181 (2001) 1-16. 
[30] R. Bharath, H. Inomata, K. Arai, K. Shoji, Y. Noguchi, Vapor-liquid equilibria for binary mixtures of carbon dioxide and fatty acid ethyl esters, Fluid Phase Equilibr. 50 (1989) 315327.

[31] J.-N. Jaubert, L. Coniglio, C. Crampon, Use of a predictive cubic equation of state to model new equilibrium data of binary systems involving fatty acid esters and supercritical carbon dioxide, Ind. Eng. Chem. Res. 39 (2000) 2623-2626.

[32] J.-N. Jaubert, L. Coniglio, F. Denet, From the Correlation of Binary Systems Involving Supercritical $\mathrm{CO}_{2}$ and Fatty Acid Esters to the Prediction of $\left(\mathrm{CO}_{2}-\right.$ Fish Oils) Phase Behavior, Ind. Eng. Chem. Res. 38 (1999) 3162-3171.

[33] J.-N. Jaubert, L. Coniglio, The Group Contribution Concept: A Useful Tool To Correlate Binary Systems and To Predict the Phase Behavior of Multicomponent Systems Involving Supercritical $\mathrm{CO}_{2}$ and Fatty Acids, Ind. Eng. Chem. Res. 38 (1999) 5011-5018.

[34] L. Coniglio, K. Knudsen, R. Gani, Model Prediction of Supercritical Fluid-Liquid Equilibria for Carbon Dioxide and Fish Oil Related Compounds, Ind. Eng. Chem. Res. 34 (1995) 24732484.

[35] L. Coniglio, K. Knudsen, R. Gani, Prediction of supercritical fluid-liquid equilibria for carbon dioxide and fish oil related compounds through the equation of state - excess function (EOS$\mathrm{g}^{\mathrm{E}}$ ) approach, Fluid Phase Equilibr.116 (1996) 510-517.

[36] V. Riha, G. Brunner, Phase equilibrium of fish oil ethyl esters with supercritical carbon dioxide, J. Supercritical Fluids, 15 (1999) 33-50.

[37] M.B. Oliveira, A.J. Queimada, G.M. Kontogeorgisc, J.A.P. Coutinho, Evaluation of the $\mathrm{CO}_{2}$ behavior in binary mixtures with alkanes, alcohols, acids and esters using the Cubic-PlusAssociation equation of state, J. of Supercritical Fluids, 55 (2011) 876-892.

[38] N. Juntarachat, R. Privat, L. Coniglio, J.N. Jaubert, Development of a predictive equation of state for $\mathrm{CO}_{2}+$ ethyl ester mixtures based on critical points measurements, J. Chem. Eng. Data, 59 (2014) 3205-3219.

[39] G. Rodriguez, E.J. Beckman, Modelling phase behavior of biodiesel related systems with CO2 using a polar version of PC-SAFT, Fluid Phase Equilibr. 485 (2019) 32-43.

[40] J. D. Haley, C. McCabe, Predicting the phase behavior of fatty acid methyl esters and their mixtures using the GC-SAFT-VR approach, Fluid Phase Equilibr. 411 (2016) 43-52.

[41] F. Llovell, L.F. Vega, Accurate modeling of supercritical $\mathrm{CO}_{2}$ for sustainable processes: Water $+\mathrm{CO}_{2}$ and $\mathrm{CO}_{2}+$ fatty acid esters mixtures, J. Supercritical Fluids, 96 (2015) 86-95.

[42] C.-C. Chen, C.-M.J. Chang, P.W. Yang, Vapor-liquid equilibria of carbon dioxide with linoleic acid, a-tocopherol and triolein at elevated pressures, Fluid Phase Equilibr. 175 (2000) $107-115$.

[43] A. Bamberger, G. Sieder, G. Maurer, High-pressure (vapor+liquid) equilibrium in binary mixtures of (carbon dioxide + water or acetic acid) at temperatures from 313 to $353 \mathrm{~K}, \mathrm{~J}$. Supercritical Fluids, 17 (2000) 97-110.

[44] H.S. Byun, K. Kunbin, M.A. McHugh, Phase behavior and modeling of supercritical carbon dioxide-organic acid mixtures, Ind. Eng. Chem. Res. 39 (2000) 4580-4587.

[45] R. Bharath, S. Yamane, H. Inomata, T. Adschiri, K. Arai, Phase equilibria of supercritical CO2 - fatty oil component binary systems, Fluid Phase Equilrbr. 83 (1993) 183-192. 
[46] J.-H. Heo, H.Y. Shin, J.-U. Park, S.N. Joung, S.Y. Kim, K.-P. Yoo, Vapor-liquid equilibria for binary mixtures of $\mathrm{CO}_{2}$ with 2-methyl-2-propanol, 2-methyl-2-butanol, octanoic acid, and decanoic acid at temperatures from $313.15 \mathrm{~K}$ to $353.15 \mathrm{~K}$ and pressures from $3 \mathrm{MPa}$ to 24 MPa, J. Chem. Eng. Data 46 (2001) 355-358.

[47] M. Zou, Z. R. Yu, and S. S. H. Rizvi, J. A. Zollweg, Fluid-liquid equilibria of ternary systems of fatty acids and fatty acid esters in supercritical $\mathrm{CO}_{2}$, J. Supercritical Fluids, 3 (1990) 85-90.

[48] F.M. Ferreira, L.P. Ramos, P.M. Ndiaye, M.L. Corazza, Phase behavior of $\left(\mathrm{CO}_{2}+\right.$ methanol + lauric acid) system, J. Chem. Thermodyn. 43 (2011) 1074-1082.

[49] L.F. Pinto, D.I. Segalen da Silva, F. Rosa da Silva, L.P. Ramos, P.M. Ndiaye, M.L. Corazza, Phase equilibrium data and thermodynamic modeling of the system $\left(\mathrm{CO}_{2}+\right.$ biodiesel + methanol) at high pressures, J. Chem. Thermodyn. 44 (2012) 57-65. 